University of Louisville

ThinkIR: The University of Louisville's Institutional Repository

Electronic Theses and Dissertations

$5-2009$

\title{
Layout design analysis for the storage area in a distribution center.
}

David William Steffey 1984-

University of Louisville

Follow this and additional works at: https://ir.library.louisville.edu/etd

\section{Recommended Citation}

Steffey, David William 1984-, "Layout design analysis for the storage area in a distribution center." (2009). Electronic Theses and Dissertations. Paper 1377.

https://doi.org/10.18297/etd/1377

This Master's Thesis is brought to you for free and open access by ThinkIR: The University of Louisville's Institutional Repository. It has been accepted for inclusion in Electronic Theses and Dissertations by an authorized administrator of ThinkIR: The University of Louisville's Institutional Repository. This title appears here courtesy of the author, who has retained all other copyrights. For more information, please contact thinkir@louisville.edu. 


\title{
LAYOUT DESIGN ANALYSIS FOR THE STORAGE AREA IN A DISTRIBUTION
} CENTER

By

David William Steffey, Jr

B.S., University of Louisville, 2008

\author{
A Thesis \\ Submitted to the Faculty of the \\ University of Louisville \\ J.B. Speed School of Engineering \\ in Partial Fulfillment of the Requirements \\ for the Professional Degree
}

MASTER OF ENGINEERING

Department of Industrial Engineering

May 2009 



\title{
LAYOUT DESIGN ANALYSIS FOR THE STORAGE AREA IN A DISTRIBUTION CENTER
}

\author{
Submitted by: \\ David William Steffey, Jr \\ A Thesis Approved On \\ (Date)
}

by the Following Reading and Examination Committee

Dr. Gail W. DePuy, Thesis Director

Dr. William E. Biles

Dr. James Lewis 


\section{ACKNOWLEDGEMENTS}

The author would like to thank multiple people for the support they provided during the completion of this thesis. I would first like to thank my fiancée, Jackie Parris, who keep pushing me to complete this thesis and make sure that I stayed on task during this process. She also provided support at all phases of this process. The second person I would like to thank is Joe Barth. He encouraged me to start this process and helped to keep me driving to the end result. I would also like to thank my thesis director, Gail DePuy, who helped to advise me on the issues I had and what I needed to do to complete this thesis. She also helped to keep me level headed and not over think things. 


\begin{abstract}
A main component of a company's supply chain is their distribution center. In a distribution center the product is brought in from the manufacturer and then shipped out either to retail stores or end users. There are five main processes that are present in all distribution centers. They are receiving, putaway, picking, packing and shipping. The picking process is the most time consuming. This is due to the amount of time it takes to travel through the storage area.

Historically, the main objective when designing the storage area is to reduce the amount of distribution center space it consumes. Recently, a new idea for a layout design using a Fishbone was proposed in the literature to reduce the amount of travel time for an employee. This fishbone design was reported to reduce the amount of travel time for an employee by $23.5 \%$ when compare to the traditional grid layout design.

This thesis will evaluate the fishbone layout for two different order fulfillment processes; unit-load and order picking. The performance of the fishbone layout in terms of travel distance and space utilization will be compared to that of a traditional grid layout.
\end{abstract}

The results for the fishbone layout storage corroborated the results presented by Meller and Gue (2006). There was a reduction in the process travel time for the unit-load and the order picking process for the new fishbone layout compared to the traditional 
layout. While these results indicate the fishbone layout reduces travel time, the traditional layout design still offers higher storage density advantages. 


\section{TABLE OF CONTENTS}

Page

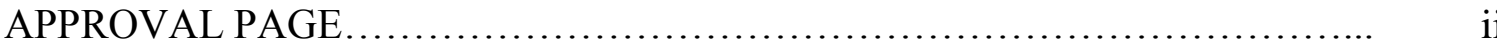

ACKNOWLEDGMENTS ............................................... iii

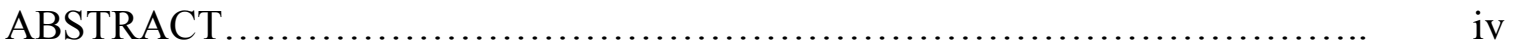

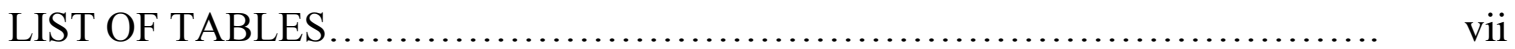

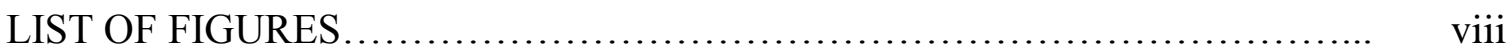

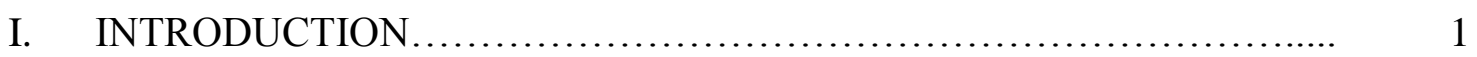

II. LITERATURE REVIEW ........................................ 4

A. Distribution Center Design.................................. 4

B. Picking...................................................... 9

III. FISHBONE LAYOUT ............................................... 13

A. Process Assumptions........................................ 14

B. Different Racking Layouts..................................... 15

C. Fishbone Layout Results....................................... 18

D. Disadvantages of the Fishbone Layout Based on Analysis of Dukic

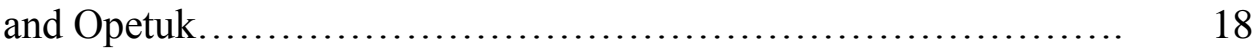

IV. METHODOLOGY ................................................. 22

A. Experimentation......................................... 22

B. Travel Distance Calculation................................... 25

V. RESULTS..................................................... 27

A. Travel Time Results....................................... 27

B. Results of Storage Space Needed.............................. 28

C. Other Issues to Consider.......................................... 29

1. Additional Racking.................................... 29

2. AS/RS Systems................................... 30

3. 3PL Applications.................................. $\quad 30$

VI. CONCLUSIONS ............................................... 33

REFERENCES ........................................................ 34

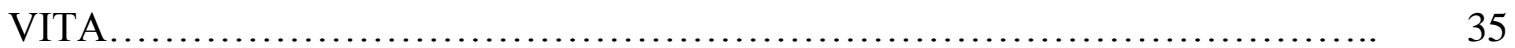




\section{LIST OF TABLES}

TABLE I Travel Distance Results of Analysis from Dukic and Opetuk

$\underline{\text { Page }}$

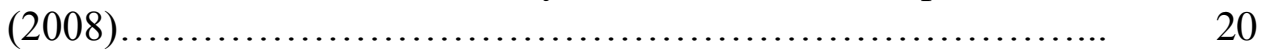

TABLE II Experimental Results.................................... 28 


\section{LIST OF FIGURES}

FIGURE 1 Fishbone Racking Model Presented by Meller and Gue (2006).....

$\underline{\text { Page }}$

FIGURE 2 Traditional Layout Model...................................

13

FIGURE 3 Cross Aisle Design............................................... 16

FIGURE 4 Fishbone Model Used for Experiment........................... 24

FIGURE 5 Sample of Distance Determination........................... 26 


\section{INTRODUCTION}

Warehousing has been a part of the consumer industry for well over a hundred years. It has come more into the lime light due to the recent growth of the internet consumer. Many consumers want a company's products quickly and they want them to be customized to their specific needs. The quicker a company can adjust to changing consumer needs, the better they will do in the market place and be able to distance themselves from their competitors. To make this a possibility, companies need to set up a supply chain that allows them to rapidly service their customer base. The cornerstone to a supply chain is the warehouse distribution centers; have a direct effect on the response time to customer demands.

Warehouse distribution centers are made up of multiple functions depending on the type of business they are supporting. Some of these business types may be: a) kitting operations where multiple items are combined into a single product for end users, b) customization which allows companies to assemble a product to an individual consumer's particular needs starting with a base product and adding on accessories or options the customer requests and (c) tech repair which allows companies to repair an individual's electronic product then return it to the consumer within forty-eight hours. While these are some of the specialized features which tailor themselves to specific industries, these are processes that are present in all distribution centers. The processes can be summed up as receiving, putaway, order picking, packing and shipping. 
Receiving and putaway make up the inbound side of the distribution center while order picking, packing and shipping are the outbound side of the distribution center. The link between these two sides is the storage area. In distribution centers the storage area consists of pallet racking. There has been a lot of research and technology poured into equipment and methods to complete the inbound and outbound processes; however, little research has been dedicated to the methodology of designing racking layouts.

The racking layout design greatly affects the amount of space and labor needed to complete inbound and outbound processes. This design is very basic concept that has been adopted by distribution centers, due to the fact that it minimizes the amount of space the storage area occupies. This design practice went without documented questioning for many years. The only real change in this type of racking configuration was the width of the drive aisle. The development of very narrow aisles (VNA) came from of the creation of material handling equipment (MHE) that enabled the movement of people and equipment throughout the storage area with the aisle width being just wide enough to allow the equipment to move through it. This development reduced the overall area consumed, but did not affect the layout design.

Meller and Gue (2006) were the first people to dispute this design. The purpose of their research was to see if there was another possible layout that minimizes of the distance an employee must travel in the storage area. They stated that the amount of time saved by implementing a less dense storage area that reduced the travel time would have a short payback period for the cost of the addition space. Meller and Gue (2006) believed this would also help to reduce the amount of equipment needed to complete the processes that take place in the storage area. In 2006, Meller and Gue developed the Fishbone 
Racking Model which reported a saving of $23.5 \%$ in cost compared to the traditional layout model based on a set of assumptions. The reporting of this amount of saving for a company interested many people in the distribution center industry.

This thesis examines the results reported by Meller and Gue (2006). It will validate the findings of Meller and Gue (2006) and will expand their research by investigating the performance of the fishbone layout when used for a different type of picking process. This will help to determine whether the results presented by Meller and Gue (2006) are unique to their model or have a broader application.

The remaining sections will discuss the process taken to develop layouts in distribution centers and discuss what picking consist of and the different methods of completing this process. Section II reviews the distribution center design research. Section III will examine the fishbone design which is the primary focus of this thesis. Section IV presents the comparative analysis between the fishbone and traditional layout. Then the specific model presented in this paper will be identified and the analysis completed on this model will be explained. The results will be presented in Section V and compared against the previous findings for this particular problem. Finally, the other points of interest surrounding this topic will be discussed. 


\section{LITERATURE REVIEW}

The layout of a distribution center has a direct impact to the amount of labor and equipment needed in the distribution center. The main goal for most distribution centers is to limit the amount of labor while increasing throughput. This is a very simple goal that has a multiple factors that can affect a company's ability to reach these goals.

\section{A. Distribution Center Design}

There are several high level steps or phases that need to be completed when designing a distribution center. Within these steps and phases are decisions and processes that need to be completed and decided upon before moving forward. These design phases presented by Rouwenhorst (2000) are concept, data acquisition, functional specifications, technical specifications, selection of means and equipment, layout and selection of planning and control policies. The primary goal of these steps is to get maximum throughput with the minimum amount of investment and operational cost. Rouwenhorst (2000) goes on to state that within each of these phases the problems are broken down into three different levels. These three levels are strategic, tactical and operational. These levels follow a top down approach instead of a bottom up.

The first and highest level is the strategic level. This level deals with decisions that have a long term affect on the layout of the distribution center. In reference to the problem presented in this thesis, the type of decisions that would be made at this level

would be the type of equipment and storage media would be used for the putaway and 
picking process. The inputs into making this decision would be product and order characteristics. From these inputs the outputs would be the type of equipment and storage media needed to handle the product. The outcome of these outputs would not be a specific answer to the problem but and sorted number of possible solutions.

Short term decisions are made at the tactical level. The outcome from the strategic level would become the inputs for these tactical decisions. Decisions are made as to the specific number of people, equipment, amount of storage media, dimensions of the storage media and the layout. The answers for these decisions would then become the inputs for the operational level questions.

The operational level decisions are ones that have to be made day in and day out. These type of decisions would be with employees that would be responsible for completing each process and where exactly the employee would put the product away. These decisions are the last step of a phase and allow the movement forward to the next phases.

Tompkins et al. (2003) present a different set of design steps. These steps are: define the problem, analyze the problem, determine the space requirements for all activities, evaluate alternatives, select the preferred design and implement the design. The first step in this process is twofold. The first part is to determine the main objective of the distribution center. During this step it is imperative to determine the products that are to be stored at the facility and the volumes associated with these products. It is also vital to determine the roll of the distribution center in the company's supply chain. The second part of this step is to define the processes and requirements in terms of the operations, equipment, personnel, and material flows involved. 
Next in the Tompkins et al. (2003) process is to analyze the problem. During this step the relationship between all the processes needs to be defined both quantitatively and qualitatively. This will help to determine whether or not a layout will be feasible due to the relationship between the processes. Only the processes that take place inside the warehouse needs to be analyzed for this step.

It is now time to determine the amount of space that is needed for all activities. This is a vital piece of the process. If the amount of space that is determined is too large or small then the ability to obtain the objective could be in jeopardy. The amount of people, equipment, and material needs to be a part of the determining the amount of space needed. Once the amount of space for each area is defined then potential layouts should be put together. During this phase it is vital to use the flows that have been determined. This will help make sure that the designs are feasible. The different possible layouts need to consider different levels of material handling equipment and labor.

After all the possible layouts are put together, it is now time to evaluate each layout. When evaluating the different layouts there are some criteria that need to be considered. The first one is cost. This is comparing the initial cost and the operational cost. A particular layout could have a higher initial cost but a lower operational cost. These costs would need to be compared over the proposed life of the distribution center. The second area of consideration is operational processes. It is important to determine which layout will allow for the smoothest flow of product through the distribution center. After all the feasible layouts have been analyzed it is now time to select the best layout for the distribution center. This decision will be based on the objectives set at the beginning of the process. If none of the layouts meet the original objectives, then the 
objectives may need to be reevaluated or the company may want to refocus the scope of this project.

The final step is to implement the layout. This is not only true for the physical layout of the warehouse but also for the technology that will be supporting the operation. Once the project moves into the implementation phase there will be a new project plan created to support the implementation.

These two layout processes are designed to help organize the development of the overall layout of the warehouse. Hassan (2002) defines the process for designing the layout of the storage area within a distribution center. The steps are taken out of a list that is to be used for the overall layout of a warehouse. These steps are storage partition, design of material handling, storage, and sortation systems, design of aisles, determining space requirements, determining the number and location of $\mathrm{I} / \mathrm{O}$ points, arrangement of storage and zone formation.

The first step in the Hassan (2002) storage design process is storage partition. In most distribution centers the storage area is separated in reserve and picking areas. This is to expectantly reduce the amount of congestion in the storage area and streamline processes. Within these two areas there could be subareas. These subareas could keep product families together or to separate out areas that need a particular type of material handling equipment.

The next step is the design of material handling equipment, storage and sortation systems. This step is dependent on successive steps which have an effect on the solution at this step. There are many decisions that are made during this step. Some of these are 
the amount and type of equipment, what area this equipment will be assigned and the flow of the product and equipment.

Thirdly, the design of aisles, need to be determined. The type of equipment that will be used in each area helps in determining the size of the aisles due to the fact the aisle has to be wide enough for the equipment to go down. The depth of these aisles will depend on the type of processes that are used. If the distribution has a very manual process then they would prefer short aisles so that an employee could move aisle to aisle very quickly, where if the process was highly automated with AS/RS system the longer aisles would help to reduce the amount of equipment needed

Once the aisle sizes are determined, it is then time to determine the space needed for the entire storage area. The height of storage media and the quantity will play a great role in the amount of space needed, as will the amount and size of the drive aisles. Another topic that needs to be considered is safety policies already defined by the company.

The next step is to determine the number and location of the $\mathrm{I} / \mathrm{O}$ points. $\mathrm{I} / \mathrm{O}$ points directly impact the level of throughput and the amount of labor for the storage area. Some of the points maybe required depending on the type of material handling equipment used. There should be multiple I/O points to allow high flexibility and accessibility to the storage area.

The second to last step in designing the storage layout is the arrangement of storage. There are three main decisions that have to be made during this step. The first one is determining the location of storage equipment in the picking and reserve areas. Secondly, is whether the assignment of items and classes to storage locations is relative 
to I/O points or to each other. The last decision to be made is the arrangement of items within each class.

The final step in design the storage area is zone formation. This step is dependent on the picking process used. If zone picking is used then this step is needed, but if order or batch picking is used then this step is not needed. This step involves dividing up the

pick areas into separate but equal zones. The size of these zones depends on the amount of people able to be assigned to a zone and vice versa.

\section{B. Picking}

In distribution centers the product is generally brought to the distribution center in whole pallet quantities. This is due to the fact that product commonly comes directly from the manufacturing plants to the distribution center. Once the pallets are unloaded from the truck into the distribution center, they are placed in the storage area. After the product is placed in the storage area, it is then ready for the outbound processes.

The first step in the outbound process is picking. Picking is the process of retrieving the correct quantity of each part, for a particular order, from the storage area. There are three different levels of picking according to Piasecki (2001), which are piece, case and pallet. These three different levels of picking refer to the level at which the items are picked. Most pallets in a warehouse have multiple cases of product on them and within these cases is a particular quantity of pieces.

Piece and case picking have four different types of picking methods that can be used. (Piasecki, 2001) These methods range from very simple in nature to ones that require additional processes to the outbound side of the warehouse to complete the 
orders. These four types of picking are basic order picking, batch picking, zone picking and wave picking. (Piasecki, 2001)

The most basic from of order picking is basic order picking. This is not usually seen in most distribution centers today due to the fact it is the most time consuming method. When using this method an order is given to one employee to complete. This employee is only allowed to pick that one order as they move throughout the predetermined pick path.

Batch picking is a very simple concept that helps to reduce travel time. To begin batch picking multiple orders need to be collected. These orders are then picked by a single employee on a solitary trip through the pick path. As the employee travels through the pick path they stop at the location for each product that is needed to complete their orders. This allows them to only have to travel the pick path once while completing multiple orders.

Zone picking involves breaking out the storage area into zones. The size of these zones depends on the amount of employees that are used to pick. The orders are picked a zone at a time. Orders will start in the first zone and that employee will pick all the products that are in that zone for that order. Then the order will be taken to the next zone for the products the order calls for in that area. This will continue through all the zones until the order is completed.

Wave picking is a more technical picking method that helps to reduce labor needed to pick the orders but adds another process to the distribution center. During wave picking, multiple orders are combined together into a single order. The picker goes through the pick path and gathers the units needed for all the orders. This means, if two 
orders call for the same part and one order needs five units and the second order needs four, then the employee would pull nine units from that location. The employee would not know the number of units needed for each order. Once the employee had picked all the products then the products would be dropped off at a consolidation area. The consolidation area would separate out the units into the individual orders.

In the research presented by Broulias et al. (2005) they compared the improvement of moving from strict, previously called basic order picking, to a more dynamic order picking. Their research compared strict to zone picking. When making this change, they saw a great reduction in the amount of time it took to complete the order picking process. There were some other changes that were made with the slotting of the product and the layout of the storage area. The author did not credit the time savings to the changes in the picking methodology but more to the change in the slotting and layout.

The previous paper looked at the savings from moving from strict or basic order picking to zone. Parikh and Meller (2007) examined whether zone or batch picking was the optimal choice. When they completed their research they found for their experiment that using zone picking created a greater workload-imbalance. They also saw that the imbalanced increased when the order size increase, the item distribution is more nonuniform and the number of waves increases. These results can be attributed to the fact that in zone picking the employee is dependent on the employee upstream from them. In batch picking the employee is only dependent on themselves, since they pick the entire orders.

The three different set of steps to follow when designing a warehouse gives a broad overview of the amount of work it takes to properly develop an optimal design. 
Developing this type of layout will help in making a distribution center a strong link in a company's supply chain. The key part of the layout is that it flows for the processes that are to be used. The most labor intensive process in a distribution center is the picking process. There are multiple processes that can be used to complete this task. These processes would need to be analyzed for a particular distribution center to determine which is optimal for that application. Batching, zone and basic order picking all have applications where one will be optimal over the other. There will also be some cases where the operation will only be able to use one of these processes due to particular circumstances. 


\section{FISHBONE LAYOUT}

As previously mentioned, Meller and Gue (2006) introduced the idea of the Fishbone Racking Model as a way to reduce the labor cost in the picking process. Their research presented dramatic results that they believed would change the mindset of many people in the industry. Their standpoint was that the additional cost to build a bigger distribution center for the increase in storage space would be paid back with labor savings from a new storage area design. The layout presented by Meller and Gue (2006) can be seen in Figure 1.

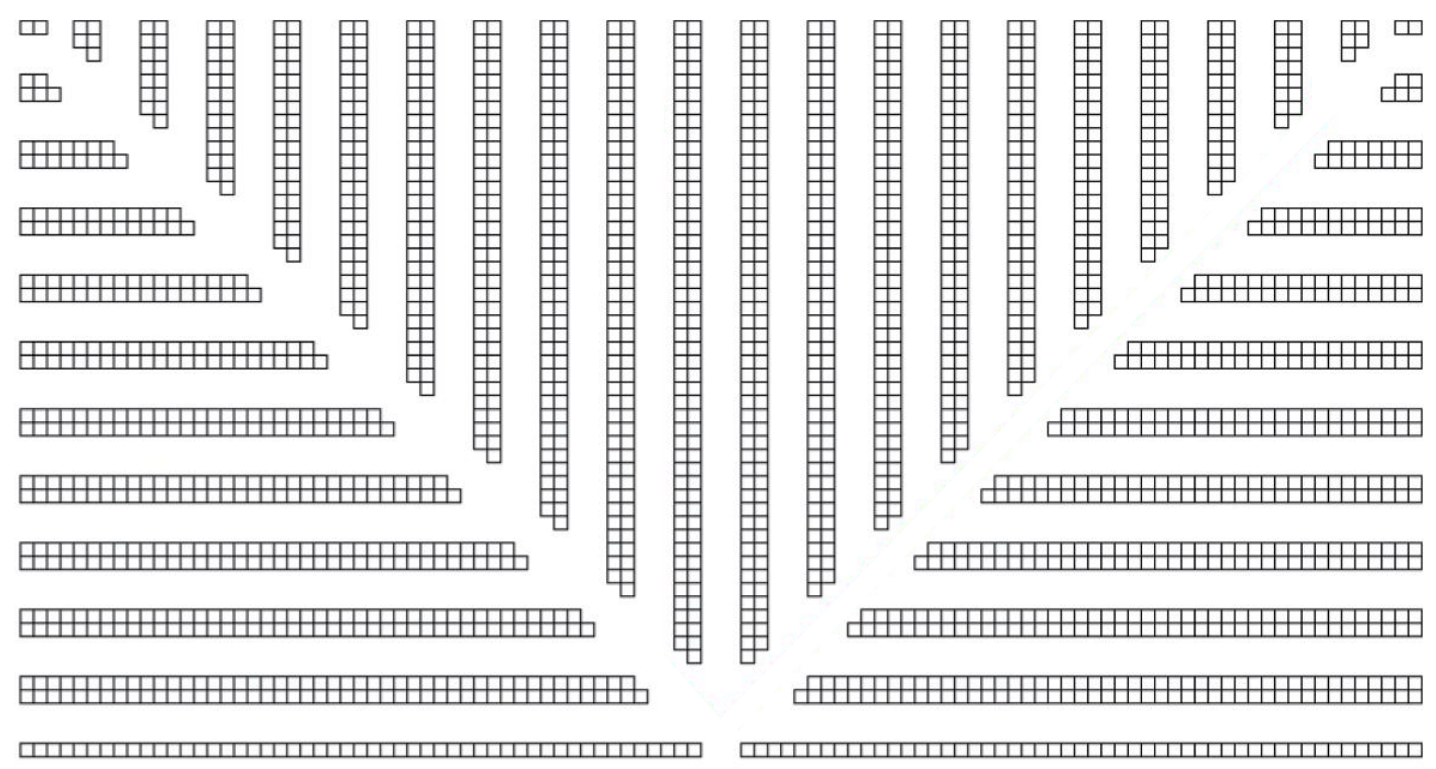

FIGURE 1 - Fishbone Racking Model Presented by Meller and Gue (2006) 


\section{A. Process Assumptions}

Meller and Gue (2006) define the assumptions of their analysis. Because of the amount of variables that could affect the travel time, Meller and Gue (2006) limited these variables to reduce the variation in their results.

The first assumption made by Meller and Gue (2006) was that the product would move in whole pallet quantities (unit loads). This means that the product would enter and leave the storage area in a whole pallet quantity. Due to the fact that most distribution center equipment is used to move only one pallet at a time, this meant that each trip in and out of the distribution center would only require the worker to travel to a single location and then back to a single in/out point. This assumption eliminates these results from applying to an order-picking process that requires employees to go to multiple locations to complete an order and then return back to the in/out point.

The next assumption was that there would not be any slotting strategy for how the product was stored. This would make each location have the same probability of where the employee would have to travel next. Slotting is the method of putting product in particular locations depending on how often that product is used to complete an outbound order. Slotting was based on Paretto's principle which states twenty percent of the products make up eighty percent of the outbound volume.

The third assumption was that all travel begins and ends at a single pick and drop off point. This allows for the model to fit with most distribution centers that have a single staging area; once the pallet is pulled from the racking, it can be moved to 
complete the outbound processes. It also gives a uniform start and end point for each trip in and out of the storage area. This helped standardize the results.

The final assumption made was eliminating the issues of physical building obstructions, congestion and the worker becoming disoriented in the storage area. Most distribution centers have support beams that take up storage locations or could possibly be in the way of a drive aisle. The assumption of no congestion also helps eliminate the possibility of the workers having to take an indirect route from one location to the next. If this was not an assumption it would be hard to determine the amount of travel time needed. The distance could change constantly depending on if other equipment or employees impede their direct path to the next location.

\section{B. Different Racking Layouts}

Meller and Gue (2006) compare two racking layouts; the traditional grid layout and the fishbone layout. The traditional layout, shown in Figure 2, consisted of rows of racking of equal length that run parallel to one another. Meller and Gue (2006) initially modified the traditional layout by introducing two diagonal drive aisles as shown in Figure 3. This cross aisle design includes a drive aisle in the center of the south side of the storage area. The drive aisle then proceeds in the northwest and northeast direction until they stop half way up on both the east and west side of the storage area. Even though this cross aisle layout is very similar to the traditional design, it produces a large reduction in travel time. Meller and Gue (2006) reported that it would reduce the travel distance by $11.2 \%$ but increase the space needed by $3 \%$ when compared to the traditional layout. 


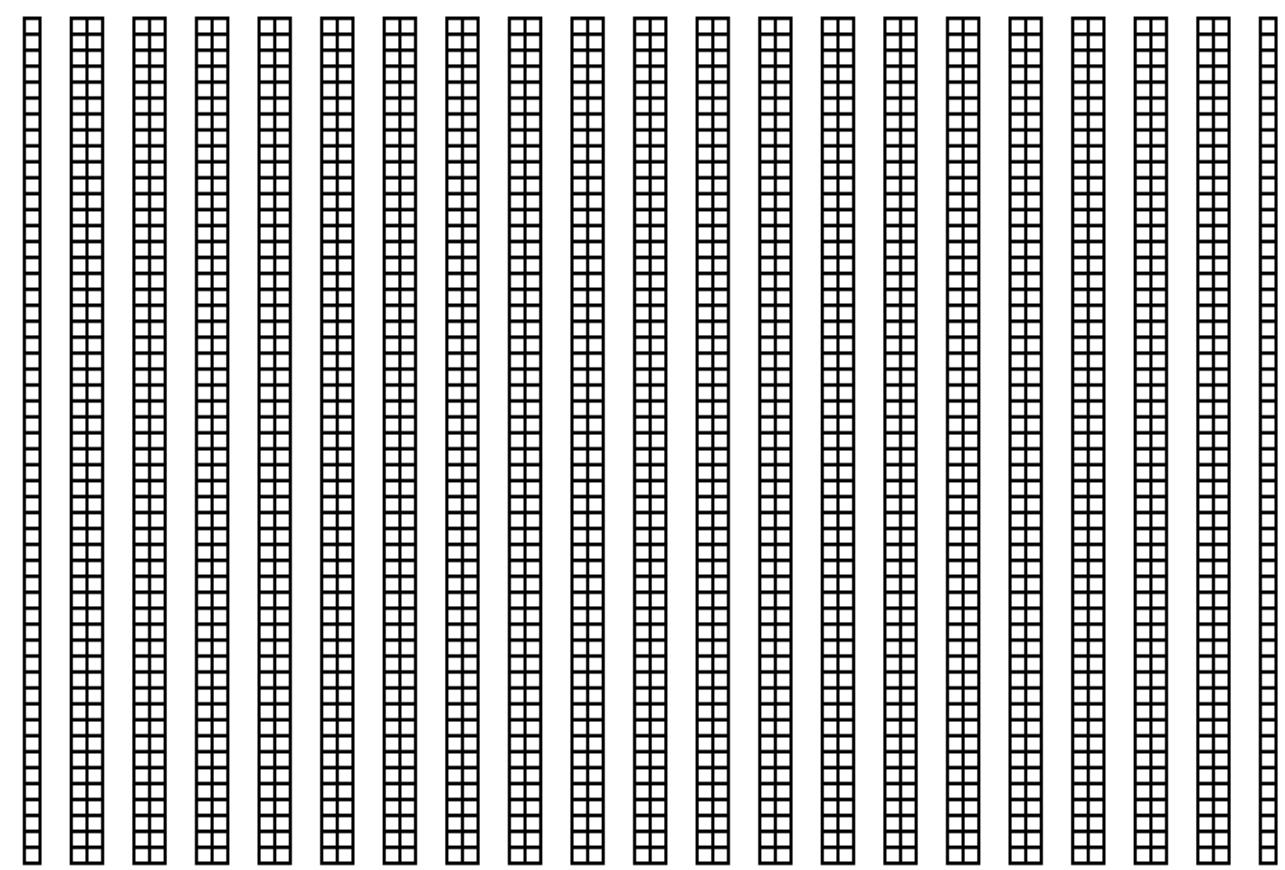

FIGURE 2 - Traditional Layout Model (Meller and Gue, 2006)

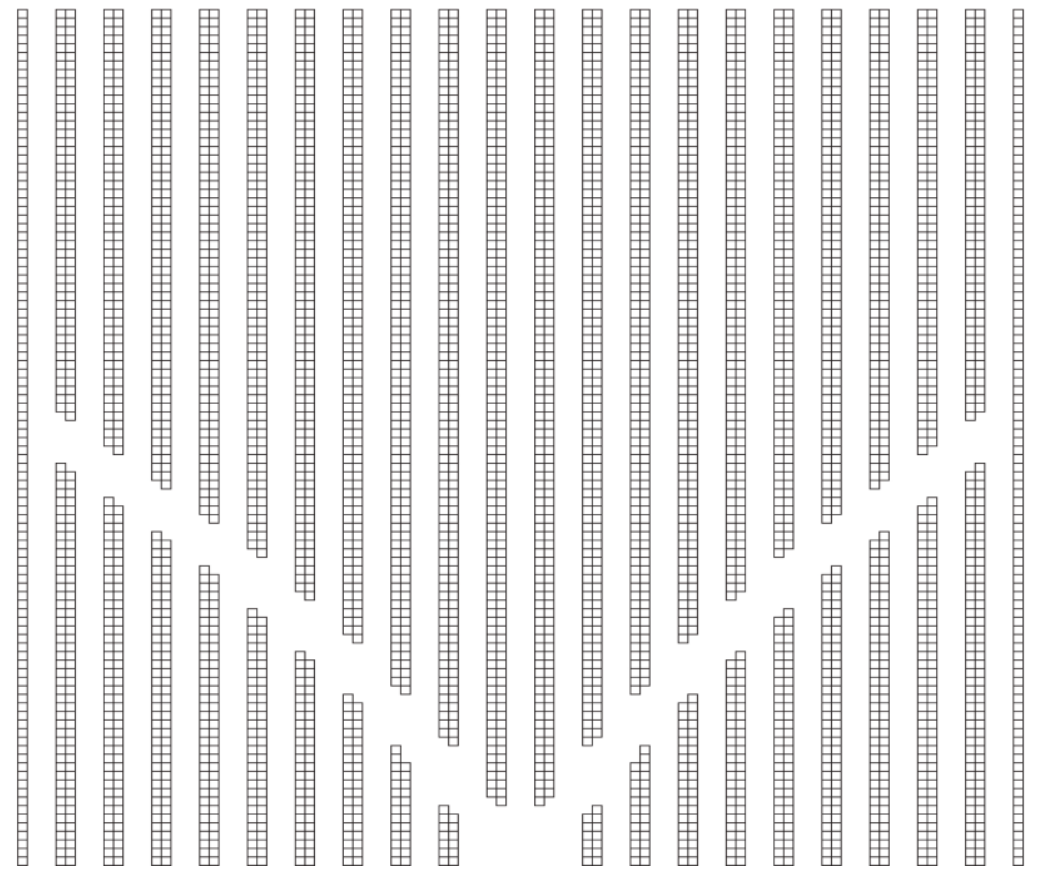

FIGURE 3 - Cross Aisle Design (Meller and Gue, 2006)

Then Meller and Gue (2006) presented the fishbone layout (see Figure 1) which reduced the travel time by $20.7 \%$. The first step in creating this design was to determine 
the aisle widths depending on which equipment the operation would use. The operation would then identify the area where the racking would be located. Once this was determined, the horizontal center of the area would need to be located along the south side. From that point, there would be two drive aisles with one going to the very northeast corner of the area and the other going to the very northwest corner. This defines the cross-section aisles that reduce travel time. At the north end of these aisles, two pallet positions would be located running in the horizontal direction with the first location up against the east or west side. The racking on the south side of the drive aisle would continue running in the horizontal direction with the predetermined aisle width inbetween every row. The amount of locations for each row would depend on how many would fit starting from the outer edge moving inward toward the cross-section aisles. This process would be used for both the east and west side of the area below the crosssection aisle.

The north side of the drive aisles would have rows for racking running in the vertical direction. These rows would follow the same strategy as the rows that were located on the south side of the drive aisle. Once the rows are completely laid out, the area should have a main V-shaped drive aisle. This layout is what the researchers referred to as the Fishbone Racking Model. This model gave them the best output out of all the models they researched using the traditional method as comparative model. 


\section{Fishbone Layout Results}

The Figure 1 fishbone racking layout showed a $20.4 \%$ reduction in travel time as determined by Meller and Gue (2006). This travel time reduction is twice as large as the reduction seen in their cross aisle layout (Figure 3 layout). As with the Figure 3 cross aisle layout, the Figure 1 fishbone layout design also increases the amount of space needed for storage. Meller and Gue (2006) also reported that this design required a 3-5\% increase in area needed for storage.

The development of the cross aisle design and the Fishbone Racking Model showed that the traditional layout was not the most optimal from a travel time perspective with the assumptions stated above. These types of results started discussions on how applicable the design was and what would happen if some of these assumptions were relaxed.

\section{Disadvantages of the Fishbone Layout Based on Analysis of Dukic and Opetuk}

Dukic and Opetuk's (2008) interest in this topic came from the results presented by Meller and Gue (2006). As mentioned above, Meller and Gue (2006) used the assumption of only unit load picks where Dukic and Opetuk (2008) wanted to relax this assumption to see if the Fishbone Racking Model was optimal for an order picking distribution center. Order picking is the process of going to multiple locations within the storage area to complete an order.

In most modern distribution centers that use order picking, a predetermined pick path is followed. There are multiple goals or advantages for a predetermined pick path. The predetermined pick path is to help the limit the possibility of an employee having to 
wait for another employee to vacate an aisle so they can enter. It also limits the amount of travel time for an employee. Lastly it prevents the employee from becoming disoriented in the storage area. There are multiple policies for determining the optimal pick path; however, the issue with these policies is that they were developed for the traditional racking layout.

Dukic and Opetuk (2008) developed three different layouts to compare. The three different layouts were: a traditional layout without a cross aisle, a traditional layout with a cross aisle and the third was the Fishbone Racking Model. Since they would be experimenting based off of an order picking model, they had to determine a pick path for each layout. They chose an S-shaped policy for their pick path. This policy is very basic in nature and therefore made it easier to apply to the Fishbone Racking Model. The Sshaped policy fit the traditional layout with and without the cross-aisle very easily. The fishbone model required them to make some decisions. They had to determine where they would start their path and how it would flow throughout the storage area. They decided that the path would start at the center of the south side of the storage area and move clockwise throughout the area as needed.

Dukic and Opetuk (2008) wanted to determine what the time difference would be for an order picking process. By comparing the amount of time it took in all three layouts to pick a ten location order and a thirty location order, they could determine which layout was optimal for their applications. In order to complete their experiment they used a simulation that would randomly select locations the employee had to visit. As in the experiment presented above each location would have an equal probability of being selected. Their results can be seen below in Table I. 


\section{TABLE I}

\section{TRAVEL DISTANCE RESULTS (IN METERS) OF ANALYSIS FROM DUKIC AND OPETUK (2008)}

\begin{tabular}{|l|c|c|c|c|c|c|}
\hline Order Size & \multicolumn{3}{|c|}{10} & \multicolumn{3}{c|}{30} \\
\hline Layout & $\begin{array}{c}\text { Within } \\
\text { Aisle }\end{array}$ & $\begin{array}{c}\text { Across } \\
\text { Aisle }\end{array}$ & $\begin{array}{c}\text { Total } \\
\text { Average }\end{array}$ & $\begin{array}{c}\text { Within } \\
\text { Aisle }\end{array}$ & $\begin{array}{c}\text { Across } \\
\text { Aisle }\end{array}$ & $\begin{array}{c}\text { Total } \\
\text { Average }\end{array}$ \\
\hline Traditional & 181.3 & 77.4 & 258.7 & 289.1 & 86.7 & 375.8 \\
\hline $\begin{array}{l}\text { Traditional } \\
\text { with Cross } \\
\text { Aisle }\end{array}$ & 116.5 & 77.4 & 193.9 & 242.3 & 86.7 & 329 \\
\hline Fishbone & 155.6 & 71.9 & 227.5 & 268.7 & 83.2 & 351.9 \\
\hline
\end{tabular}

As seen above there is a difference in the time saved between the 10-location order and the 30-location order. The 10-location order results showed that the traditional layout with the cross aisle was the optimal layout. The fishbone model had $17 \%$ longer travel time than the traditional layout with the cross aisle. The traditional model without a cross aisle has the longest travel time. The variance between the distances for the three layouts decrease for the 30-location order compared to the 10-location orders. As seen above, the fishbone layout is $7 \%$ longer than the traditional with the cross aisle which was optimal. The traditional model without the cross aisle was again the longest. Dukic and Opetuk (2008) concluded the reason the fishbone model has a longer pick path is due to the fact that is has more drive aisles that are longer than the traditional layout with the cross-section aisle. Due to the fact that they used the S-shape pick methodology, the employee would have to travel the entire length of the aisles to move on to the next aisle with their next required location.

Another result of their experimentation was the amount of space that the fishbone model consumed over the traditional layout. Meller and Gue (2006) showed an increase of $3-5 \%$ storage area was needed for the fishbone layout compared to the traditional, and 
an increase of $16 \%$ when comparing the traditional model without the cross section aisle to the fishbone model; this is three times higher than Meller and Gue (2006) presented. There was an $8 \%$ increase in area for the fishbone model when compared to the traditional layout with a cross aisle Dukic and Opetuk (2008).

The remainder of the paper will expand on the findings of Meller and Gue (2006) as well as Dukic and Opetuk (2008). Meller and Gue (2006) presented their findings based on using a unit-load picking process. The following will validate these finds and also examine the application of basic or batch order picking. This differs from the research presented by Dukic and Opetuk (2008). Dukic and Opetuk (2008) used a predetermined order path when analyzing the three layouts they developed. The research presented below discusses the results when a predetermined pick path is not utilized. 


\section{METHODOLOGY}

The remainder of this thesis will describe an analysis performed to evaluate the fishbone layout and traditional grid layout under both unit-load and order picking scenarios. The results from this analysis can be compared to the works of Meller and Gue (2006) and Dukic and Opetuk (2008). The next section will define the instrumentation, processes and results of this experiment. There will also be a discussion on what other factors a manager should consider when determining their storage layout.

\section{A. Experimentation}

The strategy and materials used to validate the results presented above are very simplistic. The materials consisted of graph paper and Microsoft Excel. Microsoft Excel was used to analyze the computation, and the graph paper allowed for a uniform way of gathering the data. The graph paper would also help with laying out the layouts and also help determine the distance needed to travel for each step of the process. Each cell on the grid paper was assumed to be a four foot by four foot square. This represented the two dimensional area a pallet would consume.

The assumptions for this experiment were a mixture of the ones presented by Meller and Gue (2006) and some additional ones. The first assumption was that there would not be any slotting methods used in the storage area which gives each location an equal probability to be selected. The second assumption was that there would be a single in/out point used for the storage area. The third assumption was that there would not be any obstruction for the employee moving from one location to the next. The fourth 
assumption was the employee would not become disoriented in the storage area and would be able to determine the shortest route to the next location. Finally, there would not be a predetermined travel path for order-picking processes.

The traditional racking model used for this experiment was designed to resemble the figure from Meller and Gue (2006). Figure 2 shows this traditional grid layout. The traditional layout begins with a single row of rack running vertically along the east side of the racking area. This row is made up of 53 pallet positions. The traditional layout consists of parallel rows of racks from the east to the west side of the storage area. Inbetween these rows are eight foot drive aisles. This traditional grid layout (Figure 2) resembles the layout of most racking in distribution centers. Arranging rows of racks in a back-to-back configuration gives the racking more stability as well as maximizes the storage density. The total number of locations for this layout was 2,120 locations per level (53 locations per row and 40 rows). This layout consumed 4,240 cubes when drawn out on the grid paper. This would equate to 67,840 square feet in a real world application.

The fishbone model used in this experiment (Figure 4) was different than what was provided by Meller and Gue (2006). This layout was created by using an eight foot drive aisle for both the $\mathrm{V}$ shaped drive aisle and the drive aisles between the rows of racking to keep the consistency between the two layouts. It was not defined what the sizes of the drive aisles were for the fishbone design presented by Meller and Gue (2006). This lead to the lower $\mathrm{V}$ of the design to have a single row of racking running horizontally on the very north and south side and 11 rows of back-to-back racking inbetween. The lengths of these rows varied depending on how many pallet positions 
would fit between the outer perimeter of the storage area and the main drive aisle. The upper $\mathrm{V}$ was made up of rows of racking running vertically. This section had 22 rows of back to back racking with eight foot drive aisles. The length of these aisles varied depending on the amount of room available from the north perimeter of the racking area to the main drive aisle. The difference between the diagram provided by Meller and Gue (2006) shown in Figure 2, and the design described above, seen in Figure 1, is the width of the drive aisles being consistent for the aisles between the racking and the $\mathrm{V}$ shaped cross aisle. As seen in Figure 1 there is a total of 2,080 locations for this layout. The grid paper area is 4,512 cubes which equates to 72,192 square feet.

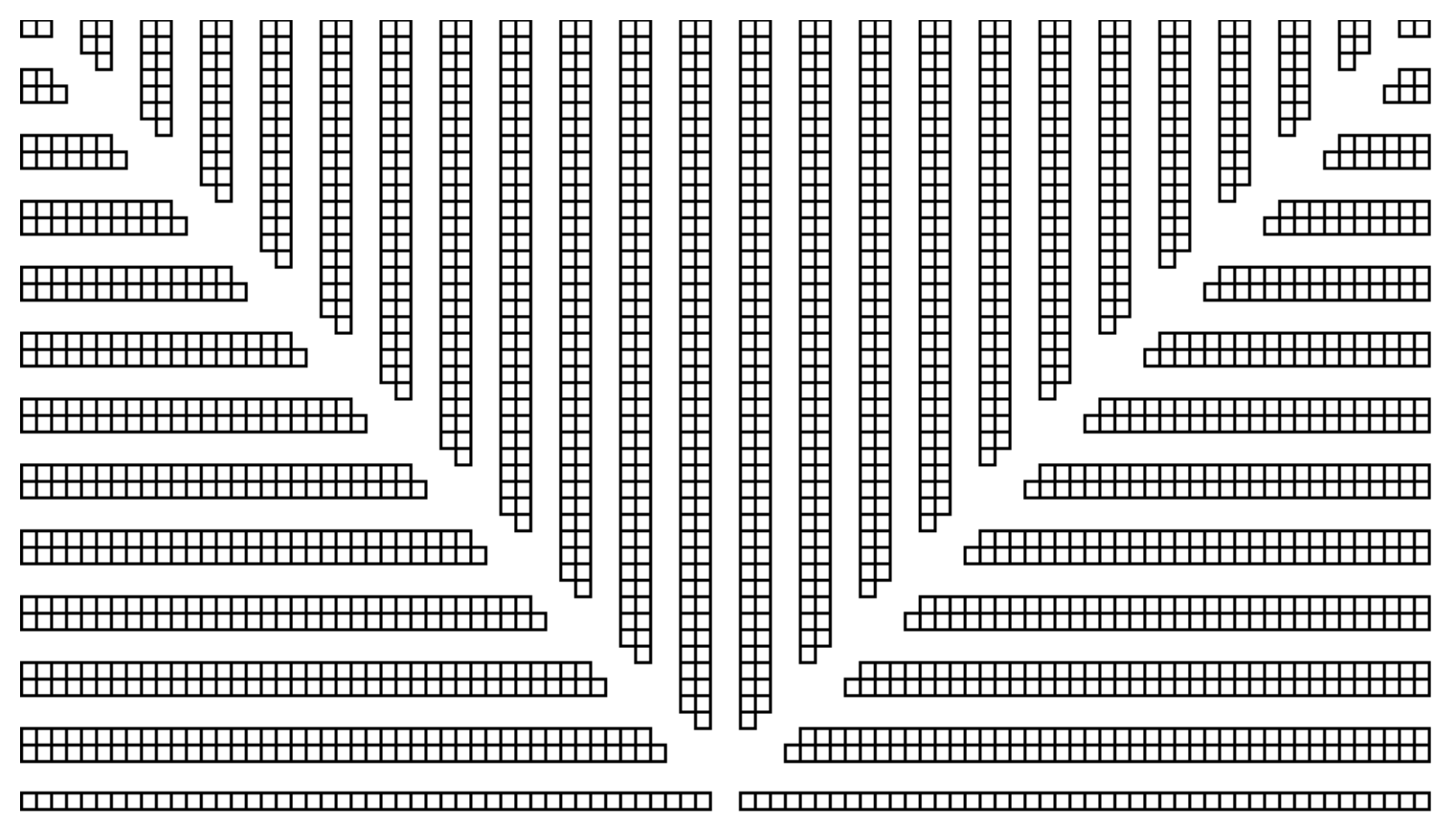

FIGURE 4 - Fishbone Model Used for Experiment 


\section{B. Travel Distance Calculation}

The main performance measure of the layouts evaluated in this research is the distance the employee has to travel to complete their task. In order to calculate that distance, the amount of blocks that the employee passed through from one location to the next was tabulated. The two other distances captured per location was the distance that the employee would have to travel from the final location to a drop off point and then from the drop off point to in/out point. Each move was broken down into the above measures. The amount of blocks that the employee had to move through was then multiplied by four to convert the number of blocks into a distance measured in feet. This process was used on both layouts.

A simple example can be seen below in Figure 5. The sample comes from the fishbone layout shown in Figure 4. This section comes for the third row of racking from the north side on the west edge of the layout. The shortest distance from each location to the next had to be determined for each possible location combination. As seen below the employee is currently in the red highlighted square. The employee is to move to the location highlighted in blue. The two possible paths that the employee could take and the amount of cubes they would pass though for each path was determined. If the employee was to turn left to move to the next location they would need to travel 9 spaces and if they went to the right it would be 11 spaces. The smallest quantity of these two distances is 9 cubes. This number is what was multiplied by four to determine that the employee would have to travel 36 linear feet. 


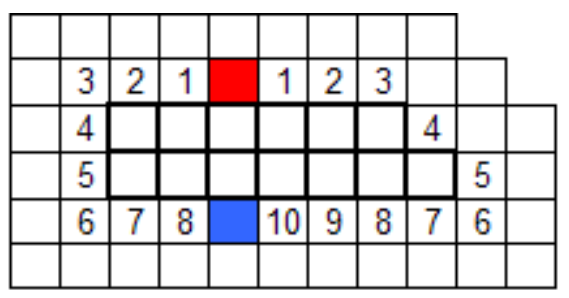

FIGURE 5 - Sample of Distance Determination

This research did not use a particular order size for each trip into the storage area. The distance that the employee would have to travel from one location to the next was determined for all possible combinations. The traditional racking model and the fishbone layout required 2,246,140 and 2,162,160 different distances to be determined respectively. The average of these distances would show which layout would minimize the distance the employee would have travel.

Dukic and Opetuk (2008) results demonstrated that as the order size increased the amount of time savings for the cross aisle traditional model over the fishbone layout decreased. This shows the larger the order size; the fishbone layout becomes more of the optimal layout than the cross aisle traditional model. This thesis determines the optimal layout for all order sizes. In most distribution centers there is not a fixed order size. The quantity fluctuates from one order to the next, thus making it difficult to apply the results presented by Dukic and Opetuk (2008) to a distribution center. 


\section{RESULTS}

The results presented below are based on the average distance the employee would have to travel from location to location, location to drop off point and drop off point to I/O point. The addition of the location to drop off point and drop point to I/O point produced the average distance for unit-load picking where the location to location was used for order picking comparisons.

\section{A. Travel Time Results}

The distance traveled between the two locations was the main focus for this experiment. Meller and Gue's (2006) main focus was the unit-load distribution center; however, Dukic and Opetuk (2008) considered an order picking environment. The difference in Dukic and Opetuk's (2008) order picking research and the one presented in this thesis is was that they set a defined pick path. For this experiment, the employee would be able to move throughout the storage area along the shortest path to their next location. The average of the shortest path for all possible combinations of locations was used to determine the distance for order picking in both layouts. The results from the unit-load and order picking process for the fishbone layout and traditional grid layout are presented in Table II. 


\section{TABLE II}

EXPERIMENTAL RESULTS (ALL DISTANCES IN FEET)

\begin{tabular}{|c|c|c|}
\cline { 2 - 3 } \multicolumn{1}{c|}{} & Unit-Load Picking & Order Picking \\
\hline Traditional Model & 198 & 243.16 \\
\hline Fishbone Model & 139.6 & 199.2 \\
\hline
\end{tabular}

The table above shows that the results presented by Meller and Gue (2006) are close in relation to the results presented in this experiment. Meller and Gue (2006) reported a reduction of $20.7 \%$ where this experiment saw $29.4 \%$ reduction in travel time for unit-load picking. Dukic and Opetuk (2008) reported that the fishbone model was the optimal model for unit-load picking in their experiment, but did not report whether or not their results were higher or lower than those reported by Meller and Gue (2006).

This experiment also showed that the fishbone model was optimal for order picking. The fishbone model in this experiment reduced the travel time by $18.1 \%$. This result is different than the one presented by Dukic and Opetuk (2008). The difference in the results is due to the use of a predetermined pick path. The use of a pick path requires an employee to exit the aisle opposite of where they enter. This makes the employee travel the whole length of the drive aisle. This experiment does not use a predetermined pick path which means the employee would be able to exit the aisle at the end closest to their next location.

\section{B. Results of Storage Space Needed}

Meller and Gue (2006) mentioned that when they conducted their experiment, 3$5 \%$ more area was needed when using the fishbone diagram instead of the traditional racking model. Dukic and Opetuk (2008) saw a higher percentage of space needed for their model. This experiment saw that an increase of $6.4 \%$ of area was needed. This 
space increase was higher than Meller and Gue (2006) but significantly lower than Dukic and Opetuk (2008). One point to note is that for this experiment the traditional model had 2,120 locations where the fishbone design had 2,080 locations. In the previous two models presented, the number of locations was consistent between the two or three layouts. With there being two percent more locations in the traditional model, this means not only did the fishbone model take up 6\% more space, but the actual area increase would be higher if the number of locations was consistent.

\section{Other Issues to Consider}

\section{Additional Racking}

One thing to consider when deciding between fishbone and traditional racking layout is the potential of growth. The traditional racking structure is very flexible when it comes to this issue. When using this layout the operation is able to add positions to any side of the storage area. This allows for additional storage without interrupting daily operations. The fishbone racking layout is a more permanent layout. In order to add pallet positions the operations must first decide which way they want to expand. Once that decision is made they would then have to identify which locations they would need to shift to keep the $\mathrm{V}$ drive aisle starting in the center of the south perimeter and running to the very northeast and northwest corners. This would cause the operation to move the racking adjacent to the drive aisle which could cause production to stop during this time.

There could also be an additional cost incurred by the operations if they used wire-guided vehicles. If the operation installed wire guidance in the main drive aisle then they would have to relocate that wire to the center of the new V drive aisle. Depending on the way the wire was connected to the power supply, they could possibly have to 
reconnect the wire for the $\mathrm{V}$ drive aisles to the wires for the side drive aisle. If they have rail guided material handling equipment, the effect would not be as great, such as having to cut the flooring to install a new wire.

\section{AS/RS Systems}

One of the main technological advances that were developed for the distribution center industry was automatic storage and retrieval systems (AS/RS). These systems are designed to be able to store and pick either pallet or case unit loads automatically without the need of human interaction. This system moves up and down racking drive aisles on railings that are centered between the two rows of racking. This system would be difficult and more expensive to implement in the fishbone diagram. In most of these systems the equipment is dedicated to a single drive aisle. The fishbone racking diagram has more drive aisles than the traditional, which would cause a greater increase in cost. It would be highly unlikely for a company to implement the fishbone model for AS/RS system due to the main advantage of the fishbone model is to reduce the amount of labor where the AS/RS will eliminate the need for labor all together.

\section{3PL Applications}

In recent years, more and more companies have started switching to a different type of supply chain model. This model is referred to as third party logistics (3PL). Third party logistics companies allow their customers to grow rapidly. Instead of companies having to construct their own distribution centers and the personnel to service it, they outsource their supply chain to a 3PL. These 3PL companies have distribution centers located throughout the country and possibly the world. They give smaller companies who do not need a full size distribution center the opportunity to compete 
against their larger counterparts. These 3PL companies have large distribution centers that companies can lease space from and they also provide the hourly and management labor to run the customer's distribution operation. Their customers save by not having to purchase the land, or be burdened with the construction cost of building a brand new distribution center. It also allows the customer's distribution operation to grow without having to worry about out-growing their current distribution center they might have constructed just a few years prior.

The main objective for a 3PL is to be able to successfully operate a company's distribution business in the smallest amount of space. The smaller the amount of space a client of the company uses, the higher revenue per square foot the company makes. This also allows the 3PL to have more space they can sell to for future clients. With the Fishbone Racking Model taking up more space within a distribution center, the revenue per square foot would drop for a 3PL. It would also increase the cost for the customer due to the fact that the customer pays a certain amount per square foot to rent the space needed for their account. Depending on the amount of space the storage takes up, the cost could be minimal or quite significant.

As mentioned before, for fishbone storage areas to grow, production would have to shut down to allow for the racking to be reconfigured. This is a big concern for 3PLs because they hold a company's success in their hands. When most companies begin to transition to a 3PL supply chain model they usually start off with a small component of their overall business. As the 3PL begins to prove themselves to their client and the client begins to see the saves from using a 3PL then they give the 3PL more of their 
business. This means an increase in the amount of storage space needed which would raise their cost if they used the fishbone model. 


\section{CONCLUSIONS}

The presentation of the fishbone racking layout has opened the eyes of many people in the distribution center industry. There are some documented advantages of this fishbone layout compared to the traditional grid layout. The amount of money that it could save a company in labor could justify the amount of money it would take to build a larger distribution center. The main questions would be how much labor would be saved and what is the additional amount of space needed. These answers will help to determine if the model is worth implementing.

The answer to these has varied between all three models presented in this paper. It varied depending on the number of locations for the models, the type of picking methodology, the predetermined pick path and the type of layout used. Even though all three of these models examined various combinations of these factors, there were not any results that were consistent.

A company looking to design a storage layout and is deciding which layout to use needs to model this for their business. The results are too dependent on the factors presented that a general conclusion cannot be made of which is best. There will be cut off points were ones advantages will out weight the others. There is also a need to for more research to determine what the optimal pick path is for the Fishbone Racking Model. This would allow for this layout to better fit itself to the order picking method. 


\section{REFERENCES}

Broulias, G.P., Marcoulaki, E.C., Chondrocoukis, G.P., \& Laios, L.G. Warehouse Management for Improved Order Picking Performance: An Application Case Study from the Wood Industry. Department of Industrial Management \& Technology, University of Piraeus.

Dukic, G. \& Opetuk, T. 2008. Analysis of Order-Picking in Warehouses with Fishbone Layout. Industrial Engineering Department, University of Zagreb.

Hassan, M. D. 2002. A framework for the design of warehouse layout. Facilities 20:432440.

Meller, R. \& Gue, K. “Fishbone Aisles.” Daily Headlines: University of Arkansas. 2006, http://dailyheadlines.uark.edu/8982.htm; accessed 15 October 2008.

Parikh, P. J. \& Meller, R. D. 2008. Selecting between batch and zone order picking strategies in a distribution center. Transportation Research Part E 44:696-719.

Piasecki, D. "Order Picking: Methods and Equipment for Piece Pick, Case Pick, and Pallet Pick Operations." Inventoryops.com. 2001, http://www.inventoryops.com/order_picking.htm; accessed 6 April 2009.

Rouwenhorst, B., Reuter B., Stockrahm, V., van Houtum, G.J., Mantel, R.J., \& Zijm, W.H.M. 2000. Warehouse design and control: Framework and literature review. European Journal of Operational Research 122:515-533.

Tompkins, J. A., White, J. A., Bozer, Y. A., \& Tanchoco, J. M. A. 2003. Facilities Planning. $3^{\text {rd }}$ Edition. New Jersey: John Wiley \& Sons, Inc. 


\section{VITA}

The author of this thesis was born on July 25,1984 . He is a graduate of Louisville Male High School in the spring of 2003. The fall of that year he entered in J.B. Speed School of Engineering at the University of Louisville. He pursued his bachelor's degree in Industrial Engineering which he obtained in the spring of 2008. Since this time he has continued his education striving to achieve a master's in the same field of study.

The author worked at UPS Supply Chain Solutions as a co-op and continued his employment after completing his co-op terms until graduation as an intern. Once the author attained his bachelor's degree he was hired on full time as a management trainee in the Steady-State IE department. He continued working as a management trainee until November of 2008 where he transition to the Post Solutions engineering group. Upon his transfer to this department he was promoted to an engineering supervisor. 